improvement and success (96.60\%). The province that is most ready for the community traffic safety checkpoint operation is Burirum. A pilot community with full capacity of community traffic safety checkpoint is more ready to operate than a pilot community with partial capacity. Number of accidents in a pilot community with full capacity of community traffic safety checkpoint is less than a pilot community with partial capacity. No accident occurred in a pilot community with full capacity of community traffic safety checkpoint which is highly ready for accident prevention activities.

\section{BUILDING THE CONVERSATION FOR HOSPITAL-BASED INJURY PREVENTION PROGRAM CAPACITY IN TEXAS, USA}

${ }^{1}$ Mary Ann Contreras, ${ }^{2}$ Courtney Edwards, ${ }^{3}$ Shelli Stephens-Stidham, ${ }^{4}$ Stewart Williams. ${ }^{1}$ JPS Health System, Fort Worth, Texas, USA; ${ }^{2}$ Parkland Health and Hospital System, Dallas, Texas, USA; ${ }^{3}$ Parkland Health and Hospital System, Dallas, Texas, USA; ${ }^{4}$ Dell Children's Medical Centre, Austin, Texas

\subsection{6/injuryprev-2016-042156.618}

Background Trauma centres in the U.S. seeking verification by the American College of Surgeons must meet certain criteria outlined in 2014 Resources for Optimal Care of the Injured Patient. The criteria state that trauma centres have an "organised and effective approach to injury prevention."

Description of the problem There are well-defined guidelines for state and local public health injury programs; however, guidance for hospital-based programs has been general and left to individual interpretation. Several U.S. trauma/injury prevention associations and organisations have expressed an interest in developing stronger guidelines for hospital-based injury prevention programs. In 2014, the Texas Governor's EMS and Trauma Advisory Council (GETAC) Injury Prevention Committee convened a work group of Texas representatives from trauma-related associations to reach consensus on standard hospital-based injury prevention program core components for Texas hospitals.

Results Standardised components were developed with input from representatives of the invited Texas organisations, including representatives from all levels of trauma designation (I-IV). Resource documents from U.S. organisations were utilised. The components were developed to be applicable to all hospital-based injury programs regardless of staffing levels or capacity.

A document, Hospital-Based Injury Prevention Components, was developed to explain and provide supporting materials for each identified core component. The document was endorsed by GETAC in November 2014 and disseminated to Texas hospital trauma and injury prevention professionals in February 2015. No legislative rule changes or requirements were associated with the endorsement. A survey link to assess use of the document was disseminated in August 2015.

Conclusions Results of the survey will be utilised to determine adoption of the document and inform future improvements and dissemination in Texas. Additionally, the Texas process has generated national attention and may be used to develop national standardised guidelines.

\section{COMMUNITY POLICE FOR SAFETY COMMUNITY}

Anon Namprasert. Khon Khen Province, Thailand

10.1136/injuryprev-2016-042156.619
Background Over alcohol drinking often caused altercation and nuisance in the community especially during festivals. Generally, community also encounter problems of drug addicted citizens who often tortured and injured people in the community which often caused violence loss of property and lives. This has been especially worried among the people in remote rural areas. This is because when there was violence in the area it was difficult for people to reach for helps from police in a timely manner. Therefore, a community police program was initiated.

Solving procedure A community police service unit has been established in the community in order to (1) support the community by setting community police in the community and (2) encourage people participation in protection measures (3) to strengthen the community to develop self-protected measures within the community

Working procedure 1. Call for community consensus for the development of police station in the area 2. If the location has been provided by the community, police department would instal necessary safety equipment in the unit 3 . Identify respectful and trustworthy citizen among the people in the community. These people will be trained to be a mediator for problem solving in the areas 4. Encourage citizen to join police volunteers. This volunteer should be able to participate in violence alleviation and protecting operation 5. Recruit citizen especially youth group that have a tendency to create nuisance in the community to be trained and assumed role as volunteer in guarding the community. 6. Allocate police officer to be supervisor and consultant to the unit of operation.

Results 1. The operation was implemented in Khon Kaen in 2013 where the project could establish 5 police operation units in each community with full supports from the people. 2 . There were 617 volunteers in 5 communities within these volunteers 66 people served as violence mediators, 136 police volunteers, 140 female volunteers for traffic accidents protection, 135 young police volunteers and 140 vulnerable youths who have been trained to serve as community guard and volunteers.

Outcome A significant drops in violence cases by $70.5 \%$, a decrease in drug related cases by $30 \%$, violence and nuisance caused by youth has reduced by $60 \%$, criminal cases dropped by $62.5 \%$ (statistics of police station at Kao Suan Kwang district, 2013) People in implemented community have been strengthen and empowered to become self- protected community.

Conclusion The development of community police unit together with strengthening systems should be an effective measures to create safe community in a sustainable procedures. The reduction in crime rate and violence in the community had been evident and the project has become an exemplary project for dissemination.

\section{0 DECREASE ROAD TRAFFIC INJURIES (RTI) MORTALITY IN UDONTHANI, THAILAND: 1997-2015}

${ }^{1}$ Daoruang Kommuangpuk, ${ }^{2}$ Anuchar Sethasathien, ${ }^{3}$ Jenjirustra Wongpratoom. ${ }^{1}$ Udonthani Hospital, Thailand; ${ }^{2}$ National Institute for Emergency Medicine, Thailand; ${ }^{3}$ Udonthani Public Health Provincial Office, Thailand

10.1136/injuryprev-2016-042156.620

The Global status report on road safety 2015, Thailand RTI mortality is the second in the world. Udonthani province is also confronted with this problem but dead case in 1997 to 2015 decrease from $816,573,494,374,424,484,474,373,382$, 330, 272, 274, 256, 302, 348, 293, 298, 309 and 247 (Budget 
year 2015) respectively. Key successful factor are 5 community safety strategies. First Injury Surveillance information that lead to second strategy risk management. Third was multidisciplinary activity. Fourth the participation from local municipality, school and work place (labour). Fifth started to work together on the easy way that made better result. Correction of many risk black spots, enforcement on alcohol related driver since 2000-2015 can decrease drink-driving from 35.34\% to 27.74\% (Budget year 2015). Post crash care that include EMS improvement, ER quality and interfacility quality care were continually implement and finally mass casualty preparedness.

\section{1 "ROAD SAFETY MANAGEMENT FOR MODEL SUB- DISTRICT" THE BEGINNING OF SUSTAINABLE ROAD SAFETY}

${ }^{1}$ Wilai Thanalad, ${ }^{2}$ Tanad Khamor, ${ }^{3}$ Patcharawadee Pirunsuntorn. ${ }^{1}$ Kranuan Crown Prince Hospital; ${ }^{2}$ District Administration Office; ${ }^{3}$ Khonkaen Provincial Public Health Office

\subsection{6/injuryprev-2016-042156.621}

Background Road accidents are the great dangers that affect both individuals and society. Thai government regards the problem as high priority and has put its efforts in planning and implementing traffic safety measures to minimise the road traffic injuries. As a result, establishing collaboration in the local private sector can be another choice for effectively preventing the road accidents.

Description of the problem Road Safety Operations Centre of Kranuan sub-district has set up a project named "Prevention of Road Traffic Accidents for Model Sub-District" with the objectives to study the development of an innovation for managing the prevention and the solutions of road traffic accidents through the promotion of collaboration in the local private sector under government support. The methodology included in-depth investigation to obtain the statistical records of road traffic accidents in the studied area. The data were analysed for the causes and the risk factors prior to returning the information to the community for further collaboratively planning its solutions. A civil society for each community was formed to establish its own constitutions and manage to have community check points to prevent the atrisk groups from going out of the areas, to conduct a survey on the hazardous environmental factors and the areas at the highand the mid-levels of risk in order to lessen the road traffic accidents, and consistently promoting the correct and safe traffic behaviours to road users through the local wire and the community radio broadcastings. The studied area was Nong-No sub-district in Kranuan district. The project had been operated during 2014-2015.

Results Nong-No sub-district is the area under jurisdiction of sub-district municipality consisting of 5 major communities. There were 7 villages with 1,294 households and population of 6,027 in total under its administration. The main road passing through the communities is Kranuan-Nampong route. The vehicles at risk consisted of 224 pickup and large trucks for agricultural products and over 1,490 motorcycles. Majority of the atrisk groups included children and youths who were students of 3 educational institutions in the area. The high-risk environments were the junctions, road curves, slippery road condition, and the roads without traffic line marking. The results from the accident surveillance in the studied area indicated the lower tendency of road traffic accident. In other words, during the fiscal years from
2012-2015, it was reported that there were $133,97,83$, and 78 accidents with $2,3,4$, and 0 number of death respectively. There was only once accident occurred on the main road in the year of 2015 while the safety helmet wearing ratio increased from $38 \%$ to $42 \%$ in the same year.

Conclusions The results suggest that the safety measures being enhanced to the large community from a small but strong community can be another choice to reduce the road traffic accidents. Due to its previous performance, the studied sub-district was rewarded as the winner for the "model sub-district in preventing road traffic accidents in Khonkaen province for the year of 2015". As a result, in the years from 2015-2016, the Road Safety Operations Centre of Kranuan sub-district committee have enhanced its operation to cover all villages in all sub-districts following the policy for managing "District Health System: DHS". It is expected to be the major approach to systematically and consistently minimising the road traffic injuries and deaths with sustainable road safety.

\section{EXPLORING THE IMPACT OF COMMUNITY-LEVEL TRAUMA AND IMPLICATIONS FOR INJURY PREVENTION}

${ }^{1}$ Rachel Davis, ${ }^{2}$ Howard Pinderhughes. ${ }^{1}$ Prevention Institute, CA, USA; ${ }^{2}$ University of California, San Francisco, USA

\subsection{6/injuryprev-2016-042156.622}

Background Communities that experience high rates of violence typically experience high levels of trauma. Trauma not only has a significant impact on development, health, and well-being, but can also be a barrier to the successful implementation of injury prevention strategies. The predominant construct for addressing trauma is currently based in a medical model at the individual level. In high-violence neighbourhoods, however, trauma can manifest at the community-level. To address this scale of trauma means not only insisting on trauma-informed care for individuals, but also exploring how to address trauma at the population level. Objective This session presents an emerging construct for population-level trauma and poses a framework to inform the development and implementation of strategies to prevent injury and trauma and promote community healing.

Results With funding from Kaiser Permanente, Prevention Institute and Dr. Howard Pinderhughes conducted a study to explore trauma at the population level, how it impacts other community health improvement efforts, and emerging strategies. The impact of trauma extends beyond the individuals who directly witness or experience violence. Trauma is also produced by structural violence, which prevents people and communities from meeting their basic needs. The result is both high levels of trauma across the population and a breakdown of social networks, social relationships and positive social norms across the community - all of which could otherwise be protective against violence and other health outcomes. The study found that the impact of trauma extends beyond individuals who directly experience violence. This results in both high levels of trauma across the population and a break-down of social networks, social relationships and positive social norms across the community - all of which could otherwise be protective against violence. In order for communities to build resilience, strategies must be implemented that build on indigenous knowledge, expertise, and leadership to yield strategies that are culturally relevant and effective 